\title{
Mitigation of Urban Pluvial Flooding: What Drives Residents' Willingness to Implement Green or Grey Stormwater Infrastructures on Their Property?
}

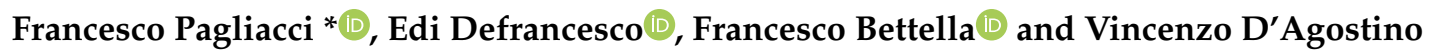 \\ Department TESAF, Territorio e Sistemi Agro-Forestali, Università Degli Studi di Padova, \\ 35020 Legnaro (PD), Italy; edi.defrancesco@unipd.it (E.D.); francesco.bettella@unipd.it (F.B.); \\ vincenzo.dagostino@unipd.it (V.D.) \\ * Correspondence: francesco.pagliacci@unipd.it
}

Received: 18 September 2020; Accepted: 29 October 2020; Published: 2 November 2020

\begin{abstract}
As a consequence of climate change, the impact of pluvial flooding is expected to increase in the next decades. Despite citizens' poor knowledge, several types of stormwater infrastructure can be implemented to mitigate the impact of future events. This paper focuses on the implementation of green and grey stormwater interventions (i.e., with or without vegetation) on private properties. Framed by the Protection Motivation Theory, a survey-based case study analysis, carried out in a pluvial flooding-prone area of the Veneto Region (Italy), highlights the main factors driving people's willingness to implement these interventions. The analysis shows that the implementation of grey stormwater infrastructures is driven by the perceived threat and the amount of past pluvial flooding damage (i.e., the direct experience as a proxy of prior knowledge) while the implementation of green stormwater infrastructures is driven also by additional factors (awareness of these interventions, age and education level of the citizens). Based on these results, lack of knowledge on innovative stormwater interventions represents a critical barrier to their implementation on private properties, and it confirms the need for specific dissemination and information activities.
\end{abstract}

Keywords: pluvial flooding; stormwater infrastructures; green infrastructures and grey infrastructures; awareness

\section{Introduction}

Due to changes in the world's climate, hydrogeological disasters have become more frequent and severe [1,2], with an increase in the frequency of episodes of heavy rainfall [3], causing pluvial flooding, i.e., the saturation of drainage systems resulting in floods, even in the absence of a river or a lake. This risk has already increased across Europe [4], and it is projected that more and more people in urban areas will suffer from higher flooding risk in the near future [2]. In some European regions, this increased occurrence and magnitude of flooding is likely to be one of the most serious issues over the coming decades: indeed, river and pluvial flooding are the most damaging types of natural hazards in Europe [5,6], with a huge impact on both urban societies and their environment [1]. Although the role played by global warming in magnifying the occurrence of pluvial flooding is still questioned (see [7]), the urbanization process, soil sealing, and steady growth of human activities in hazard-prone regions are proved to play a key role in increasing run-off and the related flood risk, hence worsening the socioeconomic impact of pluvial flooding [1,8]. In fact, pluvial flooding does not cause catastrophic damage over wide areas; rather, it usually leads to severe, albeit very localized, damage (e.g., limited to a single neighbourhood of a city).

To cope with this risk, stormwater infrastructures have been demonstrated to be effective in reducing the risk of pluvial flooding in urban areas, and they are generally classified into green and 
grey stormwater infrastructures (GreenSIs and GreySIs), depending on whether or not they include vegetation [9]. An increasing strand of the literature is focusing on citizens' attitudes towards stormwater infrastructures, although many studies have focused on the willingness to implement them in a public context, rather than on private properties [10]. Moreover, little attention is paid to pluvial flooding adaptation measures, when compared to river flooding ones. In addition, the European literature on the issue focuses more on experiences across Northern Europe than those in the Mediterranean countries, such as Italy [11].

This paper aims to contribute to filling the still existing knowledge gaps. One of the major novelties of this study is that it explores the individuals' willingness to implement either GreySIs or a combination of both GreySIs and GreenSIs. Actually, no previous studies have jointly considered both types of interventions. Moreover, the analysis addresses the interventions on private properties (i.e., small-scale interventions). To reach this goal, a survey has been conducted in the Veneto Region (Northern Italy), adopting the framework of the Protection Motivation Theory (PMT), as this is widely adopted in social sciences to analyse individual behaviours. Through a Multinomial Logit model, the differences in the factors underlying the adoption of these interventions have been jointly pointed out. The rest of the paper is structured as follows. Section 2 discusses the background of the analysis, describing the GreenSIs and GreySIs considered. Section 3 presents materials and methods, showing the case study context, adopted model and data under analysis. Section 4 reports the results, while Section 5 discusses them. Section 6 concludes.

\section{Background}

\subsection{Defining GreySIs and GreenSIs}

Urban drainage is the field involved in mitigating the risk of pluvial flooding of urban areas. Just a few decades ago, the sole aim of urban drainage was to convey stormwater away. In recent decades, however, urban drainage has largely evolved: now multiple objectives (e.g., additional water supply, increasing biodiversity, improving microclimate) drive the design of drainage infrastructures and the decision-making process [12]. This evolution leads towards the use of solutions based on natural processes and ecosystems, in order to solve both hydraulic issues and other types of societal and environmental challenges [9], also in the context of climate change. Different terms are commonly used in the scientific literature to identify these kinds of solutions (see [9,12], for an in-depth analysis of the evolution of this terminology). In this study, we refer to GreySIs and GreenSIs. In general, stormwater infrastructures include all those interventions that reduce the pluvial flooding risk of an urban area. The major difference between GreySIs and GreenSIs is the fact that the latter rely on living organisms (i.e., vegetation), thus including strategies such as evaporation, transpiration, biological absorption, storage, settling, filtration, infiltration, chemical adsorption and reuse [13].

In line with the list of infrastructures described in "The SuDS Manual" [14], the most authoritative guide to these kinds of drainage systems [12], the GreenSIs considered hereafter are those reported in the manual that include vegetation: green roofs, bioretention systems, infiltration basins, ponds and wetlands, swales. Conversely, GraySIs encompass all urban flood risk mitigation structures not including vegetation. Within this latter category we distinguish (i) traditional flood proofing structures (e.g., sump pumps, flood shields and flood walls), and (ii) innovative stormwater control measures that allow drainage, retention, detention and/or infiltration of the water runoff without relying on vegetation. Within the last category we considered the solutions described in [14] with no vegetation (i.e., rainwater harvesting systems, attenuation storage tanks, pervious pavements, filter drains and soakaways).

As mentioned, the idea to include vegetation in stormwater infrastructures, creating and improving ecosystems-rather than relying on conventional concrete-based solutions-has emerged within the last decade, to adapt to and mitigate climate change effects, while improving sustainable livelihoods and protecting biodiversity [15]. Including vegetation provides other ecosystem services in addition 
to flood risk mitigation, such as mitigation of the heat island effect and of noise, improvements in water and air quality, carbon sequestration, connection of habitat, plus biodiversity, and provision of sites for recreation or urban amenity [9,16]. Therefore, GreenSI ecosystem services improve the urban environment, mitigating climate change effects, and consideration of their monetary value is important to evaluate investments in their adoption [17]. Despite the known benefits of GreenSIs, their widespread implementation is still limited. In the UK, for example, Fenner [18] states that the implementation of GreenSIs is limited by uncertainties regarding hydrological performance and service delivery, and a lack of confidence that decision makers and communities will accept, support and take ownership of such infrastructure.

\subsection{Understanding Residents' Attitudes towards the Implementation of Stormwater Infrastructures: Literature Review}

Since the turn of the new millennium, an increasing strand of the social science literature has explored citizens' flood risk perception [19] and their awareness and willingness to implement adaptive actions. These include protective/preparedness measures—actively adopted during a flood event—and mitigation measures-i.e., passive actions implemented before the event, preventing or limiting its adverse consequences $[20,21]$.

Providing an in-depth literature review is not this paper's objective. However, it has to be mentioned that scholars take various approaches to understand individuals' flood risk perception and their behavioural responses. In their theoretical review, Birkholz et al. [22] distinguish between 'rationalist' approaches, focusing on people's cognitive and decision-making processes under risk, and 'constructivist' ones, which emphasise the influence of contextual social factors on risk perception and individuals' behaviour. Kellens et al. [23] review the models shaped in 57 case study analyses explaining people's flood risk perception and their adaptive behaviour. Most of them focus on river flooding, mainly considering preparedness actions. The adopted analyses range from descriptive approaches using no formal theories to structured theoretical frameworks. PMT and Protective Actions Decision Model (PADM) are the most used theoretical approaches. These models have a common root in the well-known theory of reasoned action and planned behaviour [24,25], which explains how perceived subjective norms, attitudes and perceived behavioural control trigger the intention to implement adaptive action and/or the actual adoption. This theory suggests that a wide range of background factors (individual, social, informational as well as institutional) influence intention and effective behaviour (see, e.g., [26] in the farmers' agro-environmental schemes adoption context).

When analysing people's flood adapting behaviour, PMT is usually adopted as it effectively emphasises that processes of threat and coping appraisal drive this behaviour more than risk perception $[27,28]$. The threat appraisal is mainly linked to perceived vulnerability, and damage severity [29] while the coping appraisal frames the individual's beliefs on the response-efficacy of the actions, the self-efficacy-i.e., the belief that she/he can perform the action-and the perceived response costs.

When considering severe river flood events, the PADM distinguishes two different coping attributes: the hazard-related attributes (response-efficacy for protecting people, protecting property, and other utility provision) and the resource-related attributes, which include perceived monetary, knowledge and skills, equipment and time requirements [30]. In addition, the Flood-risk Precautionary Behaviour (FPB) model extends PMT, by also introducing emotional factors also in explaining preparedness intention [31]. The Motivation-Intention-Volition model (MIV) [32] examines the factors triggering the adoption of protective actions in three subsequent phases of the implementation decision: the motivation phase, which is based on perceived vulnerability, expected damage, individual's coping style and self-responsibility; the intention phase, driven by evaluation of the outcome efficacy, self-efficacy and effort required; and the volition phase focused on the triggers and barriers transforming intentions into actions. 
However, when specifically focusing on stormwater infrastructures, a still limited number of studies investigate the factors affecting stakeholders' behavioural intentions or the limitations and barriers to implement adaptive measures. When exploring the willingness to implement stormwater infrastructures by residents, scholars distinguish the factors affecting the citizens' intentions at the private property scale (small scale) from that at neighbourhood/public spaces scale (urban or peri-urban large scale) [10]. However, more case studies address large scale contexts than small scale private contexts.

Residents' attitudes towards the implementation of stormwater infrastructures in public spaces involve not only individual attitudes but also their trust in institutions and some governance and institutional factors, such as their level of involvement in the decision-making process, the system of incentives (see $[9,33]$ for a review), management of maintenance costs and impact in terms of joint provision of a wide set of ecosystem services (e.g., thermal comfort, social and aesthetic values), positively impacting on the housing market [34] and/or residents' wellbeing [35,36]. Everett and Lamond [37] and Lamond and Everett [38] framed all these factors in a Social Practice model.

According to Everett and Lamond's review [39], the prerequisites for stormwater infrastructures implementation at a private property scale are (i) Desire, a concept framing awareness, understanding, acceptance and consciousness of own-responsibility in facing the risk and taking protective measures and (ii) Action, i.e., the ability to implement the measures which depends on knowledge, finance, aesthetic issues, specific context and beliefs.

Several scholars observe that a resident's lack or low level of information matters in affecting their willingness to implement stormwater infrastructures to mitigate the impact of pluvial floods [11]. Regarding this, in their systematic literature review Venkataramanan et al. [35] explicitly include 'prior knowledge' among the crucial factors explaining the willingness to implement these measures, under the theory of a planned behaviour framework, even if they conclude that only a few studies have so far explored this factor. In their review, different types of stormwater infrastructure were considered and the 'prior knowledge' issue embraces both awareness of presence and magnitude of flood hazard and information on the existing damage-limiting measures and their effectiveness. In this regard, prior personal negative flood experience is considered one of the most crucial factors of 'prior knowledge' [39-42].

Finally, residents' attitudes toward the implementation of GreenSIs is also driven by their appreciation of the wide set of GreenSIs-related ecosystem services (e.g., air quality, aesthetics) that are lacking in the GreySIs. However, it is worth noting that most people rate the flood protection functional value at the highest level among GreenSI-related ecosystem services [34,35].

\section{Materials and Methods}

\subsection{The Case Study Context}

Our case study focuses on two municipalities of the Veneto Region (i.e., Marano Vicentino and Santorso), as well as on other municipalities in the surrounding area. As shown in Figure 1, these municipalities are located on the flatlands and hills of the Venetian pre-Alps. Given its morphology, the area is characterised by a more severe rainfall regime (on average, $1100-1600 \mathrm{~mm}$ of yearly rainfall [1]) than the rest of the Region. Actually, the whole Veneto is one of the areas that show the greatest flood hazard in Italy [43,44] (with regard to the Veneto region, Sofia et al. [1] show the effect of soil sealing and climate change on flood dynamics in a long-term framework (i.e., 1900-2010), pointing out the increase in number of both flood events and flooded areas.). In addition to river flooding, in the area of Marano Vicentino and Santorso pluvial flooding may cause major damage to the local economy: although the effects of pluvial flooding are usually more confined, their social and economic burden may be huge as well. 


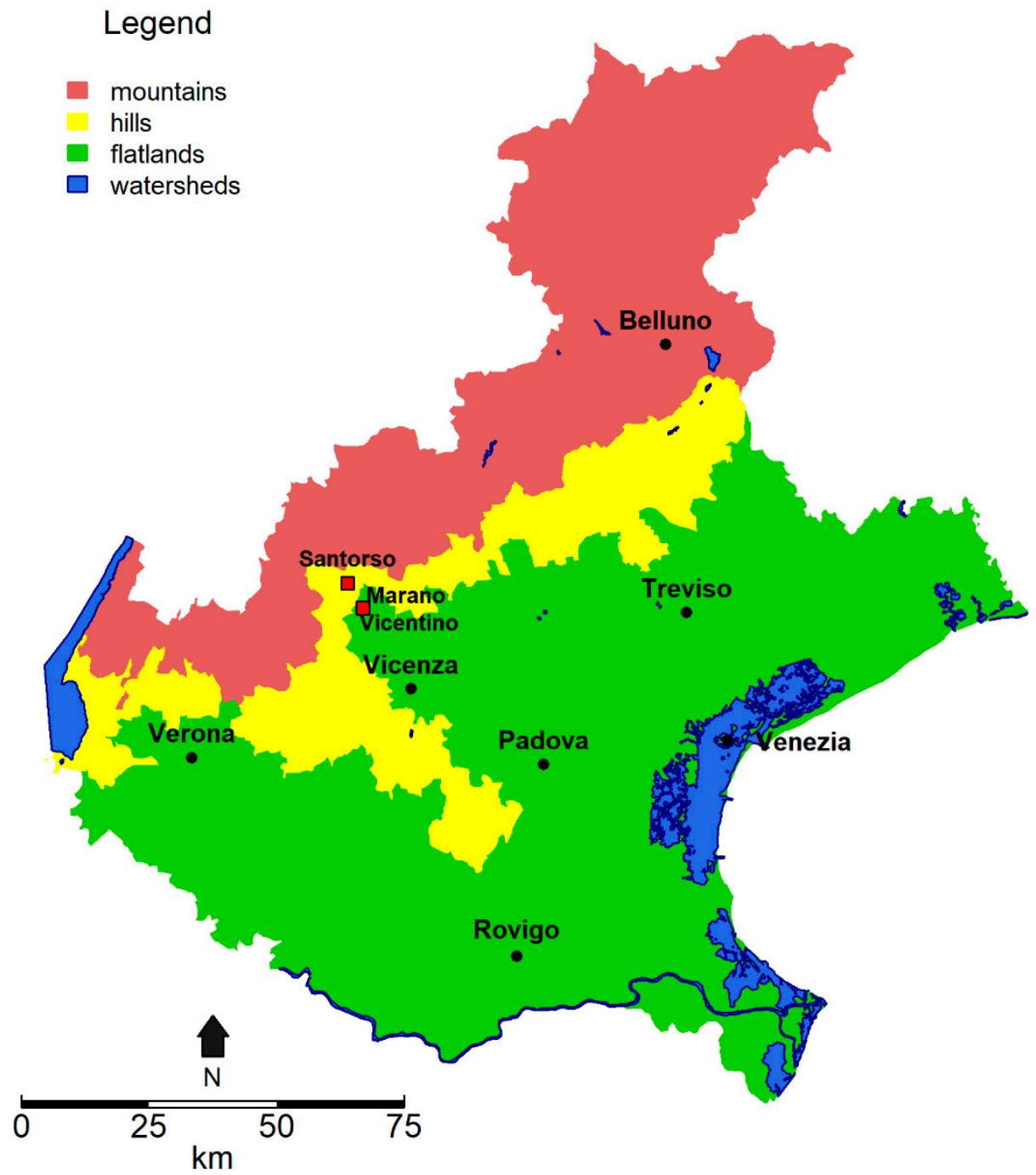

Figure 1. The study area in the Veneto Region.

Only considering the area under analysis here, it suffers from a particularly high pluvial flooding risk. In the decade 2010-2019, 20 pluvial flooding events hit Santorso, while 6 hit Marano Vicentino. Comprehensively, we estimated $€ 0.44$ million in protective and restoration costs to private properties, $€ 0.35$ million in protective and restoration costs to public properties and $€ 0.52$ million in mitigation measures in public properties. Figure 2 shows the increasing trend of protective and restoration costs to private properties over the period 2010-2019. Figure 3 shows examples of pluvial flooding in the area.

Such a pluvial flooding risk is magnified by the socioeconomic features of the area, which is characterised by widespread soil sealing, and high population density, although there are no big cities in the surroundings (the largest town in the area has less than 40,000 inhabitants). Despite the presence of a mostly rural context, most of the land is occupied by scattered homes and small blocks of flats. These types of buildings-which also include a basement-are particularly prone to pluvial flooding.

Despite the large increase in flood occurrence over time, people living in the area (as well as those in other Italian Regions) lack proper preparedness for future floods, and seem to adopt limited ex-ante mitigation actions. In addition, comparing Italian and French regions, Piacentini and Rossetto [11] show that also local stakeholders share a limited knowledge of innovative GreenSIs and their positive effects in mitigating future events. Such a lack of knowledge is the basis for the LIFE BEWARE project (Better Water Management for Advancing Resilient-communities in Europe), funded by the EU Life Programme. Among other goals, this project aims at developing adaptation capacity to urban pluvial 
flooding, through the involvement of local communities to widen the use of GreenSIs. To do that, the project focuses on the municipalities of Marano Vicentino and Santorso.

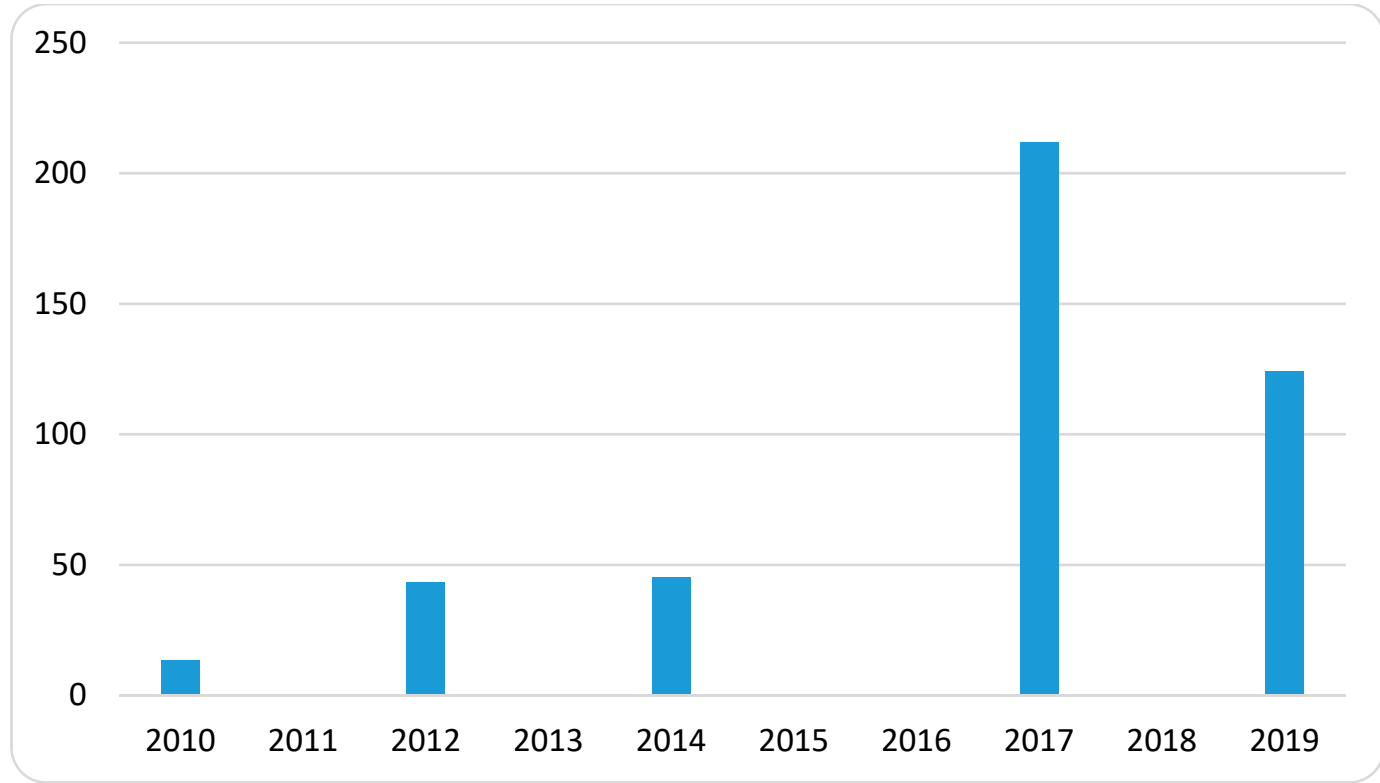

Figure 2. The increasing trend in the protective and restoration costs to private properties (in thousand $€$ ).

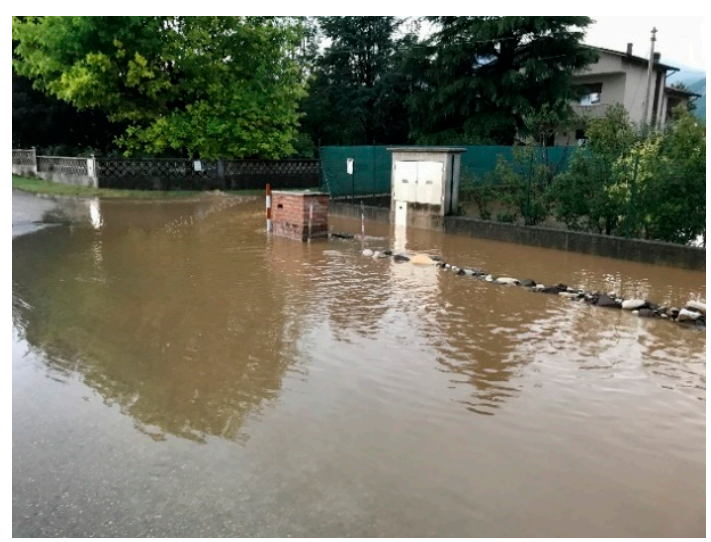

(a)

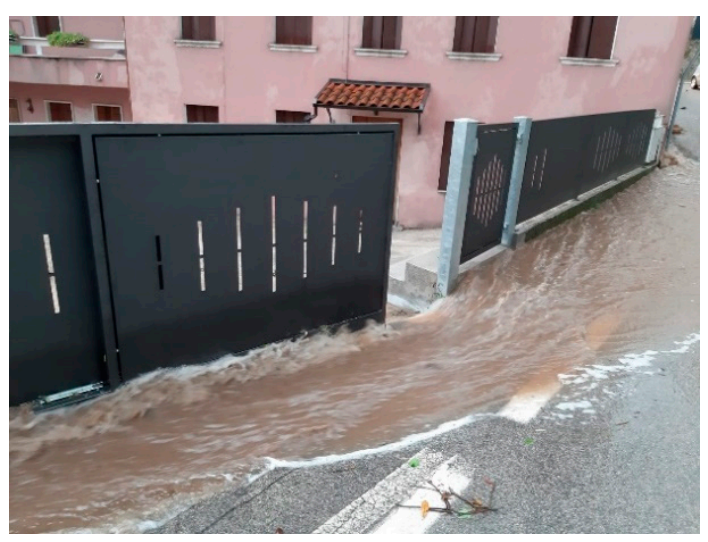

(b)

Figure 3. Examples of pluvial flooding occurred on flatland (a) and hilly (b) urbanized areas in Santorso, on 3 July 2019 (photos courtesy of Renzo Priante).

Moreover, an additional element of vulnerability for the area is represented by the institutional context. Although the Veneto Region has a large endowment of social capital-i.e., participatory potential, civic orientation, and trust in others, according to the definition by Putnam [45] — which makes local government more effective in managing hazardous events, the rural trait and the small dimensions of the impacted local communities may reduce the effectiveness of their local governments' action when addressing the complex management of extreme events (as also suggested by Pagliacci and Russo [46], with regard to different types of hazard).

When specifically considering pluvial flooding, it is worth noting that the implementation of either GreySIs or GreenSIs is lacking in the area, although pluvial flooding occurs often. Neither the local nor the national/regional governments have foreseen any particular forms of incentives for the implementation of mitigation measures. Conversely, after an adverse natural event, if the local government issues a public state of emergency (richiesta di stato di emergenza, according to the Italian regulation), the private citizens who have suffered damage to their property may claim monetary 
public compensation, which is aimed at covering restoration actions (i.e., those aimed at re-establishing the ex-ante conditions of the assets). As a consequence, these local communities share a generalised lack of knowledge about GreenSIs.

\subsection{The Model}

Adopting the PMT theoretical approach in the specific context of pluvial flooding rather than of river flooding, we test which factors affect the residents' willingness to implement either GreySIs or GreenSIs on their private property in order to mitigate the impact of urban pluvial flooding and if those factors differ. According to PMT, which considers the threat appraisal-related to perceived vulnerability and damage severity—and the coping appraisal—framed by each individual perception of self-efficacy and response-efficacy—as the main implementation drivers [27-29], the following factors are considered:

- the individual's perceived threat to his/her home as a proxy for perceived vulnerability;

- the coping appraisal factors include (i) perceived response-efficacy of GreySIs and GreenSIs; and (ii) two proxies of each resident's perceived self-efficacy when adopting adaptive measures, i.e., the implementation of protective measures in the past (e.g., pumps and flood barriers) and his/her opinion about the effectiveness of private actions in mitigating pluvial flooding impact;

- the value of direct damage that each resident has experienced as a result of the impact of pluvial floods on his/her home (damage severity). This can be considered also as a proxy for the prior knowledge' factor, according to Everett and Lamond [39];

- personal socio-demographic characteristics, whose role is generally context specific [35].

In line with the PMT literature [27,29], we expect that the perceived threat, coping appraisal factors and 'prior knowledge' positively affect people's willingness to implement both GreySIs and GreenSIs on their private property (this empirical analysis does not consider the perceived response costs, due to the lack of answers by the respondents on this question.). To test our hypotheses, a comprehensive multinomial model has been adopted. It estimates the factors affecting residents' willingness to implement GreySIs and GreenSIs, assuming the unwillingness to implement any measure as the reference baseline.

\subsection{Data}

The empirical analysis is based on the data collection, performed at the very beginning of the BEWARE project. In 2019, a direct questionnaire-based survey was conducted as part of the preliminary analyses of the project: it aimed to collect information on the awareness and willingness to implement either GreySIs or a combination of GreySIs and GreenSIs by people living in Marano Vicentino and Santorso, as well as the surrounding municipalities. The administration method was mixed: face to face interviews at the beginning of public presentations of the project (in order to avoid any possible biased answers from the respondents), and online interviews, by means of a Computer Assisted Web Interviewing (CAWI) (the CAWI survey included an explicit question about the respondent's participation in any of the public presentations of the BEWARE project. If so, the questionnaire was not administered, in order to avoid double-counting errors.). Given this administration strategy, this cannot be considered as a random sample of the households living in the area. Rather, it covers those residents who are particularly sensitive to the issue of pluvial flooding.

Comprehensively, the survey involved 265 respondents. For the purposes of this analysis, some observations were excluded, due to the presence of some missing values. Accordingly, the final set of observations, which is under consideration here, is composed of 208 respondents. Among them, $40.8 \%$ took part to the CAWI survey with a vast majority of the respondents living in the two municipalities under analysis (94 are from Santorso, and 33 are from Marano Vicentino). Other respondents are from other neighbouring municipalities. Considering sociodemographic conditions of the respondents, they are mostly men (61.1\%) and their average age is 45.9 years: only $9 \%$ are aged less than 25 while 
$37 \%$ are aged 55 and over. With regard to the tenure status of the respondents, $75.5 \%$ live in their owner-occupied homes, $16.3 \%$ are tenants in free accommodation (i.e., dwellings actually owned by their parents), and only $7.2 \%$ are tenants with a market price rent. Referring to the dwelling characteristics that might increase the vulnerability to the pluvial flooding, almost all respondents $(94.2 \%)$ live in a dwelling with some premises either on the ground floor or in the basement. Moreover, $14.4 \%$ of respondents suffered direct damage to their property, due to pluvial flooding. Finally, considering the education level of the respondents, $77.9 \%$ of the respondents achieved either the higher secondary school level or the university level. As far as stormwater infrastructures implementation is concerned, $43.3 \%$ of respondents claimed their willingness to implement at least one type. Table 1 returns the share of respondents who are willing to implement each type of GreySIs and GreenSIs.

Table 1. Share of respondents willing to implement stormwater infrastructures, by type of intervention.

\begin{tabular}{ccc}
\hline \multirow{2}{*}{ Type of Intervention } & Share of Respondents \\
\hline \multirow{3}{*}{ GreySIs } & Rainwater harvesting & $23.6 \%$ \\
\cline { 2 - 3 } & Soakaways & $13.0 \%$ \\
\cline { 2 - 3 } & Pervious pavements & $12.0 \%$ \\
\cline { 2 - 3 } & Sump pump & $11.5 \%$ \\
\cline { 2 - 3 } & Flood shields, flood walls & $5.3 \%$ \\
\cline { 2 - 3 } GreenSIs & Attenuation storage tanks & $4.3 \%$ \\
\cline { 2 - 3 } & Fioretention systems & $2.4 \%$ \\
\cline { 2 - 3 } & Infiltration basins & $9.6 \%$ \\
\cline { 2 - 3 } & Ponds and wetlands & $8.7 \%$ \\
\cline { 2 - 3 } & Swales & $8.2 \%$ \\
\cline { 2 - 3 } & Green roofs & $6.7 \%$ \\
\hline
\end{tabular}

Note: total shares exceed $100 \%$, as each respondent was allowed to indicate also more than one intervention.

However, for the purposes of the analysis, we cannot consider each single intervention separately. Thus, the dependent variable of the multinomial logit model distinguishes between respondents' willingness to implement none of the interventions (56.7\% of the respondents), only GreySIs ( $22.1 \%$ of the respondents) or a combination of both GreySIs and GreenSIs (21.2\% of the respondents). For the empirical analysis, we consider the willingness to implement GreenSIs as willingness to implement at least one of these measures, also in combination with other GreySIs. Table 2 shows the covariates that are included in the model: for each variable, the table reports its name, the factor it is a proxy for, a translation of the question of the survey, its levels (just for dummies), its statistics and the value observed in the sample.

Table 2. Model covariates (data at individual level).

\begin{tabular}{|c|c|c|c|c|c|}
\hline Label & Factor & Question in the Survey & Levels (When Dummy) & Statistic & Value \\
\hline Threat & Perceived threat & $\begin{array}{l}\text { Concerns about the fact that pluvial } \\
\text { floods represent a real problem for } \\
\text { her/his home }\end{array}$ & & Mean $^{a}$ & $2.51(0.98)$ \\
\hline Awa_grey & $\begin{array}{l}\text { GreySIs response } \\
\text { efficacy }\end{array}$ & $\begin{array}{c}\text { Awareness of the role played by grey } \\
\text { initiatives to reduce the risk of } \\
\text { flooding }{ }^{c}\end{array}$ & & Mean $^{\text {a }}$ & $2.80(1.34)$ \\
\hline Awa_green & $\begin{array}{c}\text { GeenSIs response } \\
\text { efficacy }\end{array}$ & $\begin{array}{l}\text { Awareness of the role played by } \\
\text { innovative green initiatives to reduce } \\
\text { the risk of pluvial flooding }{ }^{c}\end{array}$ & & Mean ${ }^{a}$ & $2.79(1.33)$ \\
\hline
\end{tabular}


Table 2. Cont

\begin{tabular}{|c|c|c|c|c|c|}
\hline Label & Factor & Question in the Survey & Levels (When Dummy) & Statistic & Value \\
\hline Awa_self_efficacy_d & Self-efficacy 1 & $\begin{array}{l}\text { Are you aware that individual } \\
\text { citizens can take private initiatives to } \\
\text { reduce the risk of pluvial flooding? }\end{array}$ & $1=$ Yes & $\%$ & 69.2 \\
\hline Preparedness_d & Self-efficacy 2 & $\begin{array}{l}\text { Have you bought pumps and flood } \\
\text { barriers for your home, in the past? }\end{array}$ & $1=$ Yes & $\%$ & 11.5 \\
\hline Exp & Damage experience & $\begin{array}{l}\text { Damage to the property caused by } \\
\text { pluvial floods in the last } 10 \text { years } \\
\text { (in } 000 € \text { ) }\end{array}$ & & Mean $^{a}$ & $0.90(3.88)$ \\
\hline Gender_d & Gender & Gender of the respondent & $1=$ Male & $\%$ & 61.1 \\
\hline Age & Age & Age of the respondent (years) & & Mean $^{a}$ & $45.96(16.79)$ \\
\hline Edu_d & Edu & $\begin{array}{l}\text { Highest level of education, reached by } \\
\text { the respondent }\end{array}$ & $\begin{array}{l}1=\text { Higher secondary } \\
\text { schools or University }\end{array}$ & $\%$ & 77.9 \\
\hline Child_d & Child & $\begin{array}{l}\text { Respondents with at least one minor } \\
\text { (under } 18 \text { years) in the household }\end{array}$ & $1=$ Yes & $\%$ & 29.8 \\
\hline
\end{tabular}

a Standard deviation in parentheses ${ }^{\mathrm{b}}$ Statement was measured on a 5-point Likert scale ranging from 'not at all' (1) to 'very much' (5)—Standard deviation in parentheses ${ }^{c}$ Statement was measured on a 6-point Likert scale ranging from 'non-aware' (0) to 'very highly aware' (5) for the set of five GreySIs and five GreenSIs. For each respondent and each set of stormwater infrastructures, the median value of the awareness of these interventions is taken as a proxy for the overall awareness. In the table, the mean of these median values is reported and standard deviation are in parentheses.

\section{Results}

Table 3 reports the multinomial model estimates for residents' willingness to implement stormwater infrastructures on their property. According to the model, Table 3 distinguishes between the implementation of GreySIs (1) and GreenSIs (2), both relative to the baseline model, which is the option of implementing no stormwater infrastructures at all. When considering willingness to implement GreySIs with respect to the baseline, only two variables significantly affect it: the threat appraisal factor (as an individual perception) and the prior knowledge factor, i.e., direct damage to the property caused by pluvial floods in the last 10 years. In both cases, either a larger Threat or a larger Exp increase the willingness to implement GreySIs.

With regard to the implementation of GreenSIs, significant factors are more multifaceted. Also for these interventions, both Threat and Exp are positive and significant. However, in addition, their response efficacy, namely citizens' awareness of the benefits of these innovative interventions in reducing pluvial flood risk (Awa_green), has a positive effect on their implementation. Lastly, also two sociodemographic features affect the willingness to implement GreenSIs at private level: age of the respondent and the dummy for education $\left(E d u \_d\right)$. Both have a negative coefficient. This means that older respondents and those with a higher education (either high school or university) are less likely to implement GreenSIs.

Table 3. Multinomial model estimates for residents' willingness to implement GreySIs (1) or GreenSIs (2) on their propery, relative to the baseline option (no stormwater infrastructure).

\begin{tabular}{ccc}
\hline & GreySIs & GreenSIs \\
\hline Constant & $\mathbf{( 1 )}$ & $\mathbf{( 2 )}$ \\
\hline & $-3.529 * * *$ & $-2.002^{*}$ \\
\hline Threat & $(1.173)$ & $(1.165)$ \\
\hline Awa_grey & $0.428^{*}$ & $0.479 * *$ \\
\hline & $(0.223)$ & $(0.241)$ \\
\hline & 0.043 & 0.302 \\
\hline & $(0.198)$ & $(0.226)$ \\
\hline
\end{tabular}


Table 3. Cont.

\begin{tabular}{|c|c|c|}
\hline & GreySIs & GreenSIs \\
\hline & (1) & (2) \\
\hline \multirow[t]{2}{*}{ Awa_green } & 0.116 & $0.445^{* *}$ \\
\hline & $(0.190)$ & $(0.224)$ \\
\hline \multirow[t]{2}{*}{ Awa_self_efficacy_d } & 0.314 & 0.077 \\
\hline & $(0.450)$ & $(0.501)$ \\
\hline \multirow[t]{2}{*}{ Preparedness_d } & 0.753 & -0.088 \\
\hline & $(0.591)$ & $(0.753)$ \\
\hline \multirow[t]{2}{*}{ Exp } & $0.570 * *$ & $0.658^{* *}$ \\
\hline & $(0.256)$ & $(0.256)$ \\
\hline \multirow[t]{2}{*}{ Gender_d } & 0.190 & 0.002 \\
\hline & $(0.404)$ & $(0.455)$ \\
\hline \multirow[t]{2}{*}{ Age } & -0.007 & $-0.052 * * *$ \\
\hline & $(0.013)$ & $(0.015)$ \\
\hline \multirow[t]{2}{*}{ Edu_d } & 0.871 & $-0.987 *$ \\
\hline & $(0.610)$ & $(0.567)$ \\
\hline \multirow[t]{2}{*}{ Child_d } & 0.407 & 0.713 \\
\hline & $(0.407)$ & $(0.440)$ \\
\hline Observations & 208 & 208 \\
\hline Akaike Information Criterion (AIC) & 378.028 & 378.028 \\
\hline Schwarz's Bayesian criterion (BIC) & 451.454 & 451.454 \\
\hline
\end{tabular}

Note: ${ }^{*} p$-value $<0.1 ;{ }^{* *} p$-value $<0.05 ;{ }^{* * *} p$-value $<0.01$. Standard errors are reported in parentheses.

\section{Discussion}

Most of these results are in line with those of the very limited literature on the willingness to implement stormwater infrastructures on private properties.

Firstly, as far as overall stormwater infrastructure implementation is concerned, the analysis performed here finds that $43 \%$ are willing to implement at least one type, but just $21 \%$ are willing to implement at least one type of GreenSIs. These results are almost in line with those observed by Yu et al. [10], who focus on Shanghai City, and by Baptiste et al. [47], who consider Syracuse, NY (USA). According to the former study, around 31\% of people are willing to implement GreenSIs in private space. According to the latter, a moderate willingness to implement GreenSIs is observed. In general terms, willingness to implement stormwater infrastructures seems to be greater when considering public interventions than private ones [10,35].

Among the main drivers that trigger the willingness to implement these interventions in the Veneto Region, three factors emerge: the threat appraisal factor, prior knowledge factor, and response efficacy. In addition to these, also a couple of sociodemographic variables are found to have a relationship with the dependent variable, at least GreenSIs.

Previous studies have widely stressed the positive role of threat appraisal factor (Threat) as an underlying driver for the willingness to implement both GreySIs and GreenSIs. Terpstra and Lindell [30] observe that risk perception plays a significant role in the intention to adopt some types of flood hazard adjustments. Everett and Lamond [39] (p. 512) claim that "households must be aware of the possibility of flooding if they are to take action". In stressing that such a general awareness is not yet particularly widespread, they suggest the importance of this driver for a proper implementation of stormwater infrastructures at property level. In particular, Papagiannaki et al. [31] find that risk 
perception and worry represent a key mechanism among Greek citizens for the adoption of flood-risk precautionary behaviour. Both current preparedness and preparedness intention are stimulated by these perceptual and emotional mechanisms. Indeed, Mondino et al. [40] show that both awareness and preparedness may weaken over time, especially in the absence of adverse events which reinforce the threat appraisal. With regard to the Veneto Region, a survey conducted by Weyrich et al. [2] shows that an increased perception of vulnerability increases people's motivation to protect themselves, at least for those who have already undertaken some types of structural interventions. Lastly, Yu et al. [10], who just focus on GreenSIs, claim that those people with a greater perception of pluvial flood risk are more prone to implement future green interventions.

Similar to the threat appraisal factor (and strictly connected to it), the prior knowledge factor (with the variable Exp as proxy, i.e., the value of direct damage experienced in the past) also positively drives the willingness to implement both GreySIs and GreenSIs. In fact, this issue is less studied. In their literature review, Venkataramanan et al. [35] observe that experience of flooding, albeit important, emerges less frequently as a measure to improve attitudes of citizens towards the implementation of green infrastructures. Moreover, also according to Baptiste (2014), the major findings that concern the role played by knowledge are contrasting. Despite that, Baptiste [48] recalls that the population's past experiences may drive people's behaviour. This driver is of utmost importance especially when a pro-environmental behaviour largely benefits from a wider citizens' base, individually adopting it. Moreover, past experience can explain high levels of environmental knowledge, hence strong pro-environmental behavioral intentions. According to this approach, still in the US context, Baptiste et al. [47] observe that lived experience actually triggers citizens' willingness to implement stormwater infrastructures. In a completely different context, i.e., China, Yu et al. [10] also find a statistically significant relationship between direct past experience of pluvial flood and residents' willingness to implement some types of GreenSIs. Grothmann and Reusswig [27]—who consider flood experience-find partially different results, suggesting that past experience actually triggers the adoption of prevention actions by citizens. However, it seems that past personal experience is not a necessary condition for their adoption: in some cases, one third of the people interviewed have reported precautionary behaviour, even though floods had never affected them.

When considering the GreenSIs, some additional factors play a role in driving people's willingness to implement them. Indeed, neither a former knowledge of the hazard nor a previous direct experience of adverse events can alone explain the willingness to implement these interventions. The response efficacy and some additional sociodemographic characteristics also matter.

With regard to the response efficacy (Awa_green), it is worth noting that also the awareness that people have about the role of innovative green initiatives in order to reduce the risk of future pluvial flooding plays a significant role when it comes to the willingness to implement GreenSIs. Yu et al. [10] include the awareness of the green infrastructure as a main trigger for their implementation at private level, finding an overall and positive effect on it. Baptiste et al. [47] discuss the role of knowledge, specifying the importance of that about the effectiveness of GreenSIs. Similarly, in the literature review by Venkataramanan et al. [35], the role of awareness of these interventions (as a synonym for familiarity with them) is included among the main triggering factors for their implementation. However, Venkataramanan et al. [35] also note that several studies in the literature point out that such an awareness is generally lacking. This might be explained by the existence of non-consistent definitions of GreenSIs, making it hard to "gauge people's awareness on a nebulous concept" [35] (p. 10).

Lastly, only two sociodemographic factors matter: age and education. Among these factors-which often, especially in this type of analysis, have limited explanatory power (see [47])—age is still included, as this variable is expected to affect both GreenSIs direct knowledge and their perception, thus affecting citizens' attitudes by citizens, especially with regard to public infrastructure [49]. However, different empirical studies do not converge onto consistent results, with regard to age. Actually, the negative sign found in this analysis for this variable is consistent with what was observed by Carlet [49], who claims 
that older respondents are less willing to adopt green infrastructures. Opposite results are found by Byrne et al. [50], although they refer to public interventions in China, and by Venkataramanan et al. [35]. According to their literature review, age is often positively and significantly correlated with more positive attitudes towards GreenSIs [51], showing also a stronger preference for natural areas than younger people [52]. However, it is worth noting that Yu et al. [10] also find that people with more free time have a greater willingness to participate. In this case (and according to Byrne et al. [50]) elderly people have on average more free time.

With regard to education $\left(E d u_{-} d\right)$, the past literature on this topic reports contrasting findings. Venkataramanan et al. [35] observe that, just in a few cases, higher education positively correlates with higher value for green infrastructures. A positive correlation between higher education level and the residents' willingness to implement GreenSIs in private space is observed by Yu et al. [10], while a negative impact of education on the willingness to implement GreenSIs is observed by Baptiste et al. [47], but in their case elementary school level positively influences the implementation of green infrastructures, only if a saving is accrued. This should implicitly mean that those with lower socio-economic status (namely, a lower education level, in the US context) are more willing to implement these measures to provide some addition savings. In the Italian case study, this explanation is not so convincing. Rather, in the context of the Veneto Region, where so many small and medium enterprises (SMEs) have flourished since the late 1960s, many entrepreneurs have attained a lower education level. In this case, this variable is actually able to encompass a sort of income effect. As a further possible explanation of this finding in Veneto, it could be argued that more educated people consider the individual adoption of GreenSIs as non-effective in reducing the flood risk in their property. This perception could be driven by the severe regime of rainfall experienced, on the one hand, and by the low adoption rate of these measures in the area, on the other. Indeed, some studies (e.g., [9]) argue that only a multiple adoption of GreenSIs can lead to a more significant change in run-off regime. However, the influence of education level needs to be further investigated.

The fact that willingness to implement stormwater infrastructures is mostly driven by the threat appraisal and prior experience of direct damage, in connection with the response efficacy, at least for the GreenSIs, is to some extent confirmed if we consider a further question, that was included in the survey targeting only those respondents who had declared to be unwilling to implement any of the stormwater infrastructures. In particular, that question was aimed at investigating the reasons behind their decision (Table 4). Even when considering this sub-sample of respondents, strong evidence emerges that lack of threat (i.e., "A sense of not being personally exposed to the pluvial flood risk") together with "lack of knowledge of the interventions and their benefits" play a large role in motivating such a choice.

Table 4. Reasons motivating the unwillingness to implement any stormwater infrastructures.

\begin{tabular}{cc}
\hline Reason & $\%$ of Answers \\
\hline A sense of not being personally exposed to the pluvial flood risk & $67.4 \%$ \\
\hline $\begin{array}{c}\text { Lack of direct responsibility for any decisions on these } \\
\text { interventions (e.g., tenants living in a rented flat) }\end{array}$ & $11.6 \%$ \\
\hline Lack of knowledge of the interventions and their benefits & $7.0 \%$ \\
\hline Interest in the interventions but lack of knowledge of their costs & $4.7 \%$ \\
\hline Interest in the intervention but costs too high & $4.7 \%$ \\
\hline $\begin{array}{c}\text { Ineffectiveness of the intervention, because single individuals' } \\
\text { action cannot reduce their exposure to risk }\end{array}$ & $2.3 \%$ \\
\hline Lack of awareness of having to deal with this problem personally & $2.3 \%$ \\
\hline
\end{tabular}




\section{Conclusions}

This paper has investigated the main drivers of the implementation of both GreySIs and GreenSIs on private properties, by carrying out a survey-based case study analysis in a pluvial flooding-prone area of the Veneto Region, under the framework of the PMT. The analysis has shown that the implementation of these infrastructures is mostly driven by the perceived threat and by the direct experience (i.e., a proxy of prior knowledge), but also awareness and other sociodemographic factors matter when considering GreenSIs.

Based on these results (which combine both GreySIs and GreenSIs), some barriers on their wider implementation clearly emerge: these barriers must be acknowledged and eventually reduced in order to obtain a significant implementation of green infrastructure on private properties. Although both the former perceived vulnerability and the prior knowledge due to the direct experience of a damage positively affect the willingness to implement both GreySIs and GreenSIs, the limited awareness about these interventions (and in particular about the greener and the more innovative ones) is the most critical barrier for their implementation. Such a critical lack of awareness leaves ample room for specific policy measures by local governments and other stakeholders, aimed at increasing such an awareness among the general public.

Moreover, public interventions should inform citizens on a wide set of characteristics of GreySIs and GreenSIs, such as their technical aspects and the implementing and managing costs for private citizens. Moreover, citizens should also be informed about the overall ecosystem service benefits, delivered by the GreenSIs, and the fact that damage from pluvial flooding can be significantly reduced through a wide adoption of those small-scale interventions on private properties. In addition, public authorities should also be encouraged in providing financial incentives to citizens, in order to prompt the initial diffusion of those interventions: while fiscal incentives are largely adopted for energy and seismic renovation in the Italian case, this is not true for the implementation of stormwater infrastructures.

Actually, both economic incentives and an effective information provision of the benefits of these interventions are crucial in triggering the initial implementation of these interventions. Then, social influence (i.e., social pressure) mechanisms might enhance the implementation rate within single local communities, through a more proactive participation of the citizens. The dissemination and information activities of the BEWARE Project contribute to this. They include demonstration pilots, whose spillover effects are essential to prompt private citizens' initiatives. In particular, this project will effectively communicate the wider set of environmental benefits produced by GreenSIs, by means of some implemented interventions. Unfortunately, these effects have not been explored here, given the specific context of the analysis (i.e., the ex-ante project's situation). Future studies will overcome the limitations of this work.

Author Contributions: E.D., F.B. and V.D. participated in the initial research and questionnaire design. F.B. and V.D. provided the background knowledge about flooding, GreySIs and GreenSIs, providing the related literature review and text. E.D. carried out the literature review. F.P. addressed the methodological issues, analyzed the results and discussed them. E.D. and F.P. wrote the paper. V.D. provided funding acquisition and contributed with F.B. to the revision of the first version of the present paper. All authors have read and agreed to the published version of the manuscript.

Funding: This research was funded by BEWARE Life project, grant number LIFE17 GIC/IT/000091.

Acknowledgments: The authors thank Giulia Roder for her help in designing the questionnaire and in administering the survey, they thank the BEWARE project manager, Antonio De Martin, for supporting the administration of the questionnaires during the public presentations. The authors also thank the anonymous reviewers and the editor for their valuable comments and suggestions for improving the paper. The usual disclaimers apply.

Conflicts of Interest: The authors declare no conflict of interest. The funders had no role in the design of the study; in the collection, analyses, or interpretation of data; in the writing of the manuscript, or in the decision to publish the results. 


\section{References}

1. Sofia, G.; Roder, G.; Dalla Fontana, G.; Tarolli, P. Flood dynamics in urbanised landscapes: 100 years of climate and humans' interaction. Sci. Rep. 2017, 7, 40527. [CrossRef] [PubMed]

2. Weyrich, P.; Mondino, E.; Borga, M.; Di Baldassarre, G.; Patt, A.; Scolobig, A. A flood-risk-oriented, dynamic protection motivation framework to explain risk reduction behaviours. Nat. Hazards Earth Syst. Sci. 2020, 20, 287-298. [CrossRef]

3. IPCC. Managing the Risks of Extreme Events and Disasters to Advance Climate Change Adaptation, Special Report of the Intergovernmental Panel on Climate Change; Intergovernmental Panel on Climate Change: Cambridge, UK; New York, NY, USA, 2012. Available online: https://www.ipcc.ch/pdf/special-reports/srex/SREX_Full_ Report.pdf (accessed on 19 August 2020).

4. Nissen, K.M.; Ulbrich, U. Increasing frequencies and changing characteristics of heavy precipitation events threatening infrastructure in Europe under climate change. Nat. Hazards Earth Syst. Sci. 2017, 17, 1177-1190. [CrossRef]

5. European Environment Agency. Green Infrastructure and Flood Management. Promoting Cost-Efficient Flood Risk Reduction via Green Infrastructure Solutions; EEA Report No 14/2017; Publications Office of the European Union: Luxembourg, 2017. [CrossRef]

6. Blöschl, G.; Hall, J.; Viglione, A.; Perdigão, R.A.; Parajka, J.; Merz, B.; Lun, D.; Arheimer, B.; Aronica, G.T.; Bilibashi, A.; et al. Changing climate both increases and decreases European river floods. Nature 2019, 573, 108-111. [CrossRef] [PubMed]

7. Visser, H.; Petersen, A.C.; Ligtvoet, W. On the relation between weather-related disaster impacts, vulnerability and climate change. Clim. Chang. 2014, 125, 461-477. [CrossRef]

8. Carter, J.G. Climate change adaptation in European cities. Curr. Opin. Environ. Sustain. 2011, 3, $193-198$. [CrossRef]

9. Ruangpan, L.; Vojinovic, Z.; Di Sabatino, S.; Sandra Leo, S.; Capobianco, V.; Oen, A.M.P.; McClain, M.E.; Lopez-Gunn, E. Nature-based solutions for hydro-meteorological risk reduction: A state-of-the-art review of the research area. Nat. Hazards Earth Syst. Sci. 2020, 20, 243-270. [CrossRef]

10. Yu, Y.; Xu, H.; Wang, X.; Wen, J.; Du, S.; Zhang, M.; Ke, Q. Residents' willingness to participate in green infrastructure: Spatial differences and influence factors in Shanghai, China. Sustainability 2019, 11, 5396. [CrossRef]

11. Piacentini, S.M.; Rossetto, R. Attitude and actual behaviour towards water-related green infrastructures and sustainable drainage systems in four north-western Mediterranean Regions of Italy and France. Water 2020, 12, 1474. [CrossRef]

12. Fletcher, T.D.; William Shuster, W.; Hunt, W.F.; Ashley, R.; Butler, D.; Arthur, S.; Trowsdale, S.; Barraud, S.; Semadeni-Davies, A.; Bertrand-Krajewski, J.-L.; et al. SUDS, LID, BMPs, WSUD and more-The evolution and application of terminology surrounding urban drainage. Urban Water J. 2015, 12, 525-542. [CrossRef]

13. Taguchi, V.J.; Weiss, P.T.; Gulliver, J.S.; Klein, M.R.; Hozalski, R.M.; Baker, L.A.; Finlay, J.C.; Keeler, B.L.; Nieber, J.L. It is not easy being green: Recognizing unintended consequences of green stormwater infrastructure. Water 2020, 12, 522. [CrossRef]

14. CIRIA. The SUDS Manual; CIRIA Report No. C697; CIRIA: Dundee, Scotland, 2007.

15. Nature-Based Solutions to Address Global Societal Challenges; Cohen-Shacham, E.; Walters, G.; Janzen, C.; Maginnis, S. (Eds.) IUCN: Gland, Switzerland, 2016. [CrossRef]

16. Ossa-Moreno, J.; Smith, K.M.; Mijic, A. Economic analysis of wider benefits to facilitate SuDS uptake in London, UK. Sustain. Cities Soc. 2017, 28, 411-419. [CrossRef]

17. Vincent, S.U.; Radhakrishnan, M.; Hayde, L.; Pathirana, A. Enhancing the economic value of large investments in Sustainable Drainage Systems (SuDS) through inclusion of ecosystems services benefits. Water 2017, 9, 841. [CrossRef]

18. Fenner, R. Spatial evaluation of multiple benefits to encourage multi-functional design of sustainable drainage in blue-green cities. Water 2017, 9, 953. [CrossRef]

19. Diez-Herrero, A.; Garrote, J. Flood risk analysis and assessment, applications and uncertainties: A bibliometric review. Water 2020, 12, 2050. [CrossRef]

20. Lindell, M.K.; Perry, R.W. Communicating Environmental Risk in Multi-Ethnic Communities; Sage Publication: Thousand Oaks, CA, USA, 2004. 
21. UNISDR (United Nations Office for Disaster Risk Reduction). Sendai Framework for Disaster Risk Reduction 2015-2030; UNISDR: Geneva, Switzerland, 2015.

22. Birkholz, S.; Muro, M.; Jeffrey, P.; Smith, H.M. Rethinking the relationship between flood risk perception and flood management. Sci. Total Environ. 2014, 478, 12-20. [CrossRef]

23. Kellens, W.; Terpstra, T.; De Maeyer, P. Perception and communication of flood risks: A systematic review of empirical research. Risk Anal. 2013, 33, 24-49. [CrossRef]

24. Fishbein, M.; Ajzen, I. Beliefs, Attitude, Intention and Behaviour; Addison-Wesley: Reading, MA, USA, 1975.

25. Ajzen, I. The theory of planned behavior. Organ. Behav. Hum. Dec. 1991, 50, 179-211. [CrossRef]

26. Mettepenningen, E.; Vandermeulen, V.; Delaet, K.; Van Huylenbroeck, G.; Wailes, E.J. Investigating the influence of the institutional organisation of agri-environmental schemes on scheme adoption. Land Use Policy 2013, 33, 20-30. [CrossRef]

27. Grothmann, T.; Reusswig, F. People at risk of flooding: Why some residents take precautionary action while others do not. Nat. Hazards 2006, 38, 101-120. [CrossRef]

28. Bubeck, P.; Botzen, W.J.W.; Aerts, J.C.J.H. A review of risk perceptions and other factors that influence flood mitigation behavior. Risk Anal. 2012, 32, 1481-1495. [CrossRef]

29. Zaalberg, R.; Midden, C.; Meijnders, A.; McCalley, T. Prevention, adaptation, and threat denial: Flooding experiences in the Netherlands. Risk Anal. 2009, 29, 1759-1778. [CrossRef] [PubMed]

30. Terpstra, T.; Lindell, M.K. Citizens' perceptions of flood hazard adjustments: An application of the Protective Action Decision Model. Environ. Behav. 2012, 45, 993-1018. [CrossRef]

31. Papagiannaki, K.; Kotroni, V.; Lagouvardos, K.; Papagiannakis, G. How awareness and confidence affect flood-risk precautionary behavior of Greek citizens: The role of perceptual and emotional mechanisms. Nat. Hazards Earth Syst. Sci. 2019, 19, 1329-1346. [CrossRef]

32. Martens, T.; Garrelts, H.; Gruneberg, H.; Lange, H. Taking the heterogeneity of citizens into account: Flood risk communication in coastal cities-A case study of Bremen. Nat. Hazards Earth Syst. Sci. 2009, 9, 1931-1940. [CrossRef]

33. Gimenez-Maranges, M.; Breuste, J.; Hof, A. Sustainable drainage systems for transitioning to sustainable urban flood management in the European Union: A review. J. Clean. Prod. 2020, 255, 1-16. [CrossRef]

34. Williams, J.B.; Jose, R.; Moobela, C.; Hutchinson, D.J.; Wise, R.; Gaterell, M. Residents' perceptions of sustainable drainage systems as highly functional blue green infrastructure. Landscape Urban Plan. 2019, 190, 1-10. [CrossRef]

35. Venkataramanan, V.; Lopez, D.; McCuskey, D.J.; Kiefus, D.; McDonald, R.I.; Miller, W.M.; Packman, A.I.; Young, S.L. Knowledge, attitudes, intentions, and behavior related to green infrastructure for flood management: A systematic literature review. Sci. Total Environ. 2020, 720, 1-14. [CrossRef]

36. Matthews, T.; Lo, A.Y.; Byrne, J.A. Reconceptualizing green infrastructure for climate change adaptation: Barriers to adoption and drivers for uptake by spatial planners. Landsc. Urban Plan. 2015, 138, 155-163. [CrossRef]

37. Everett, G.; Lamond, J. Considering the value of community engagement for (co-)producing blue-green infrastructure. WIT Trans. Built Environ. 2018, 184, 1-13. [CrossRef]

38. Lamond, J.; Everett, G. Sustainable Blue-Green Infrastructure: A social practice approach to understanding community preferences and stewardship. Landsc. Urban Plan. 2019, 191, 1-10. [CrossRef]

39. Everett, G.; Lamond, J. Household behaviour in installing property-level flood adaptations: A literature review. WIT Trans. Ecol. Environ. 2013, 179, 511-522. [CrossRef]

40. Mondino, E.; Scolobig, A.; Borga, M.; Albrecht, F.; Märd, J.; Weyrich, P.; Di Baldassarre, G. Exploring changes in hydrogeological risk awareness and preparedness over time: A case study in northeastern Italy. Hydrol. Sci. J. 2020, 65, 1049-1059. [CrossRef]

41. Botzen, W.J.W.; Aerts, J.C.J.H.; Van den Bergh, J.C.J.M. Dependence of flood risk perceptions on socioeconomic and objective risk factors. Water Resour. Res. 2009, 45, 1-15. [CrossRef]

42. Santoro, S.; Pluchinotta, I.; Pagano, A.; Pengal, P.; Cokan, B.; Giordano, R. Assessing stakeholders' risk perception to promote Nature Based Solutions as flood protection strategies: The case of the Glinščica river (Slovenia). Sci. Total Environ. 2019, 655, 188-201. [CrossRef] 
43. Trigila, A.; Iadanza, C.; Bussettini, M.; Lastoria, B. Dissesto Idrogeologico in Italia: Pericolosità e Indicatori di Rischio-Edizione 2018. ISPRA, Rapporti 287/2018. Available online: https://www.isprambiente.gov.it/files2018/ pubblicazioni/rapporti/rapporto-dissesto-idrogeologico/Rapporto_Dissesto_Idrogeologico_ISPRA_287_ 2018_Web.pdf (accessed on 23 October 2020).

44. Pagliacci, F.; Russo, M. Multi-hazard, exposure and vulnerability in Italian municipalities. In Resilience and Urban Disasters. Surviving Cities; Borsekova, K., Nijkamp, P., Eds.; Edward Elgar Publishing: Cheltenham, UK, 2019; pp. 175-198.

45. Putnam, R.D.; Leonardi, R.; Nanetti, R.Y. Making Democracy Work: Civic Traditions in Modern Italy; Princeton University Press: Princeton, CA, USA, 1994.

46. Pagliacci, F.; Russo, M. Be (and have) good neighbours! Factors of vulnerability in the case of multiple hazards. Ecol. Indic. 2020, 111. [CrossRef]

47. Baptiste, A.K.; Foley, C.; Smardon, R. Understanding urban neighborhood differences in willingness to implement green infrastructure measures: A case study of Syracuse, NY. Landsc. Urban Plan. 2015, 136, 1-12. [CrossRef]

48. Baptiste, A.K. "Experience is a great teacher": Citizens' reception of a proposal for the implementation of green infrastructure as stormwater management technology. Community Dev. J. 2014, 45, 337-352. [CrossRef]

49. Carlet, F. Understanding attitudes toward adoption of green infrastructure: A case study of US municipal officials. Environ. Sci. Policy 2015, 51, 65-76. [CrossRef]

50. Byrne, J.A.; Lob, A.Y.; Jianjun, Y. Residents' understanding of the role of green infrastructure for climate change adaptation in Hangzhou, China. Landsc. Urban Plan. 2015, 138, 132-143. [CrossRef]

51. Wang, Y.; Bakker, F.; de Groot, R.; Wörtche, H. Effect of ecosystem services provided by urban green infrastructure on indoor environment: A literature review. Build. Environ. 2017, 77, 88-100. [CrossRef]

52. Williams, L.T. The Botanical Biodiversity of Urban Greenspace and the Influence of Social and Cultural Factors on the Perception of These Spaces: A Multidisciplinary Approach. Ph.D. Thesis, State University of New York at Binghamton, Binghamton, NY, USA, 2012.

Publisher's Note: MDPI stays neutral with regard to jurisdictional claims in published maps and institutional affiliations.

(C) 2020 by the authors. Licensee MDPI, Basel, Switzerland. This article is an open access article distributed under the terms and conditions of the Creative Commons Attribution (CC BY) license (http://creativecommons.org/licenses/by/4.0/). 